\title{
Tumoral calcinosis of buttock in a patient with end stage kidney disease on haemodialysis
}

\section{Ashik Hayat ${ }^{1,2 *}$ \\ ${ }^{1}$ Department of Nephrology, Taranaki Base Hospital, New Zealand \\ ${ }^{2}$ Department of Medicine, University of Auckland, New Zealand}

\section{Clinical Image}

Patients with End-stage Kidney Disease (ESKD) on renal replacement therapy (RRT) are at high risk of extraosseous metastatic calcifications at multiple sites, which includes widespread arterial calcification, cardiac valvular calcification, and soft tissues calcium deposits. Tumoral calcinosis (TC) and calciphylaxis are two dreaded consequences of metastatic soft tissues calcium phosphate complex deposits in patients with ESKD with very poor outcome [1].

A 71-year-old female patient with ESKD secondary to systemic sclerosis on hemodialysis (HD) for last four years, presents with progressively increasing soft tissue swellings involving, both her buttocks over last one year. The swellings were non-tender and firm in consistency. Her X- rays revealed TC in both her buttocks and upper thigh, showing marked progression since the last study done 6 months prior. Vascular calcification was also noted in the pelvis [2] (Figure 1).

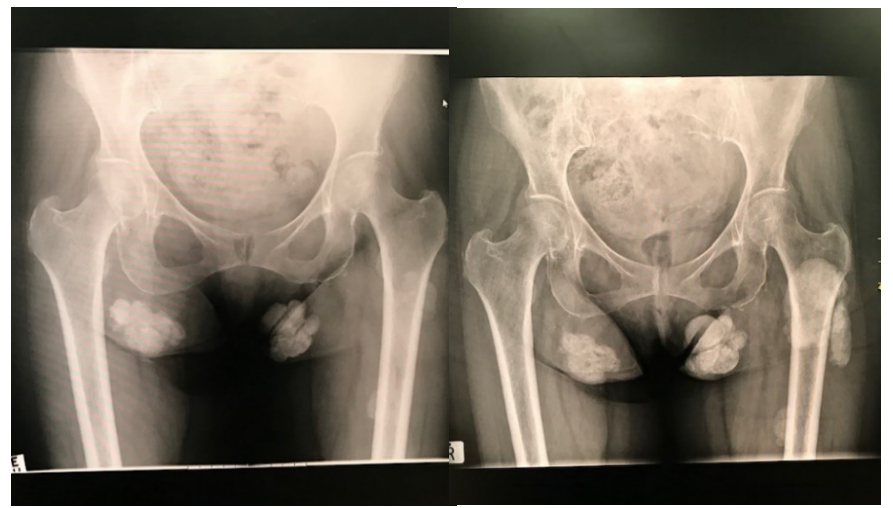

Figure 1. Subcutaneous calcifications in patient with end stage kidney disease on dialysis with tertiary hyperparathyroidism

Copyright: (C2020 Hayat A. This is an open-access article distributed under the terms of the Creative Commons Attribution License, which permits unrestricted use, distribution, and reproduction in any medium, provided the original author and source are credited.
She is on 4 hours 3 times a week HD with dialysis clearance within the target range. Her serum calcium was $2.8 \mathrm{mmol} / \mathrm{L}$, serum phosphate of $2 \mathrm{mmol} / \mathrm{L}$ and parathyroid hormone level of $60-90 \mathrm{pmol} / \mathrm{L}$. She did not improve with treatment with phosphate binders; Vitamin D. There were no improvements in the swellings with further treatment with sodium thiosulfate and Cinacalcet and aggressive dialysis. Parathyroidectomy was declined in view of high surgical risk [3].

\section{References}

1. Hayat A, Shahid K (2019) Complete resolution of tumoral calcinosis in a patient on peritoneal dialysis with cinacalcet. Perit Dial Int 39: 292-294.

2. Chu HY, Chu P, Lin Y-F, Chou H-K, Lin S-H (2011) Uremic tumoral calcinosis in patients on peritoneal dialysis; clinical, radiologic and laboratory features. Perit Dial Int 31: 430-439.

3. Maioli ME, Delfino VDA, Guerra ACDZ, Kunii LF, Frange RFN (2017) Reversal of uremic tumoral calcinosis by optimization of clinical treatment of bone and mineral metabolism disorder. J Bras Nefrol 39: 217-219. 